\title{
Correction to: Investigating Cocrystallization of Carbamazepine with Structurally Compatible Coformers: New Cocrystal and Eutectic Phases with Enhanced Dissolution
}

\author{
Indumathi Sathisaran $^{1}$ and Sameer Vishvanath Dalvi ${ }^{2,3}$
}

published online 3 February 2021

Correction to: AAPS PharmSciTech volume 22, Article number: 29 (2021) https://doi.org/10.1208/s12249-020-01888-6

In the original article, only two supplemental figs. (S1 and S30) in the ESM were published, whereas 37 figs. (S2-S29 and S31-S39), a Table S1 and a reference were not.

In addition, the authors requested that reference number 75 be removed during the proofing process. The reference was not removed.

The original article has been corrected.

Publisher's Note Springer Nature remains neutral with regard to jurisdictional claims in published maps and institutional affiliations.

The online version of the original article can be found at https:// doi.org/10.1208/s12249-020-01888-6

\footnotetext{
${ }^{1}$ Biological Engineering, Indian Institute of Technology Gandhina-gar, Palaj, Gujarat 382355, India.

${ }^{2}$ Chemical Engineering, Indian Institute of Technology Gandhinagar, Palaj, Gujarat 382355, India.

${ }^{3}$ To whom correspondence should be addressed. (e-mail: sameervd@iitgn.ac.in)
} 